\title{
Laurence Mathey-Maille, Écritures du passé. Histoires des ducs de Normandie
}

Isabelle Guyot-Bachy

\section{OpenEdition}

1 Journals

Édition électronique

URL : http://journals.openedition.org/studifrancesi/9128

DOI : 10.4000/studifrancesi.9128

ISSN : 2427-5856

Éditeur

Rosenberg \& Sellier

Édition imprimée

Date de publication : 1 juin 2008

Pagination : 163

ISSN : 0039-2944

\section{Référence électronique}

Isabelle Guyot-Bachy, "Laurence Mathey-Maille, Écritures du passé. Histoires des ducs de Normandie », Studi Francesi [En ligne], 154 (LII | I) | 2008, mis en ligne le 30 novembre 2015, consulté le 11 janvier 2021. URL : http://journals.openedition.org/studifrancesi/9128 ; DOI : https://doi.org/10.4000/ studifrancesi.9128

Ce document a été généré automatiquement le 11 janvier 2021.

\section{(c) (†) $\odot$}

Studi Francesi è distribuita con Licenza Creative Commons Attribuzione - Non commerciale - Non opere derivate 4.0 Internazionale. 


\title{
Laurence Mathey-Maille, Écritures du passé. Histoires des ducs de Normandie
}

\author{
Isabelle Guyot-Bachy
}

\section{RÉFÉRENCE}

LAURENCE MATHEY-MAILle, Écritures du passé. Histoires des ducs de Normandie, Paris, Honoré

Champion, 2007, pp. 292.

1 «Comment interpréter la prétention de l'histoire quand elle construit son récit à reconstruire quelque chose du passé?». Cette question posée par Paul Ricoeur dans Temps et Récit (1985) est au cœur de la thèse de Lettres soutenue par Laurence MatheyMaille et du livre qu'elle en a tiré.

2 Afin d'apporter sa contribution au débat sur les rapports entre écriture et histoire, entre temps et récit, L. M.-M. a choisi comme pôle d'observation l'historiographie médiévale et plus particulièrement l'exemple des historiens normands des $\mathrm{XI}^{\mathrm{e}}-\mathrm{XII}^{\mathrm{e}}$ siècles qui ont, plus tôt qu'ailleurs, mis la langue vernaculaire au service de l'écriture de l'histoire des ducs de Normandie.

3 Le pari de l'auteur était ambitieux: il s'agissait de mener une enquête qui dépasserait les perspectives strictement sociologiques (telles qu'elles ont pu être ouvertes par G.M. Spiegel) ou strictement littéraires pour tenter de saisir l'acte de naissance d'une écriture spécifique de l'histoire.

4 Les auteurs retenus, tous historiens-poètes, sont au nombre de quatre: Wace et son Roman de Rou (1160-1170), Benoît de Sainte-Maure, auteur de la Chronique des ducs de Normandie (vers 1174), Jordan Fantosme et sa Chronique (vers 1175) et Dudon de SaintQuentin dont le De moribus et actis primorum Normannie ducum, en dépit de sa différence linguistique (c'est la seule œuvre latine du corpus), est la véritable «matrice» de l'histoire ducale normande et constitue le point de départ obligé de l'enquête. 
5 Le plan de l'ouvrage s'ordonne en deux grandes parties. La première est exclusivement consacrée à l'analyse de la temporalité. L'auteur, qui a su tirer le plus grand profit des travaux des spécialistes de l'historiographie médiévale, démontre que «ses» auteurs, sans être à proprement parler des chroniqueurs, ont une réelle capacité à penser le temps, tout en l'adaptant à l'esthétique et à la logique du récit. À l'intérieur d'une structure commune, qui est celle d'un ordre généalogique et lignager, les auteurs savent aussi faire preuve de liberté, chacun ayant son approche personnelle du rythme du récit et du sens à donner à l'événement. L.M.-M. met aussi en évidence (ch. III) la présence de filtres idéologiques bien perceptibles dans les reconstructions narratives: idéologie chevaleresque, trifonctionnalité sociale, mais surtout phénomène de «rétroprojection» qui conduit les auteurs à une actualisation politique du passé en fonction du spectacle de l'histoire contemporaine.

Dans la seconde partie, il s'agit davantage de comparer les formes littéraires adoptées par les uns et les autres, afin de saisir la gestation de l'écriture historique. Le premier chapitre de cette seconde partie traite ainsi de l'écriture hagiographique propre à Dudon de Saint-Quentin et de la façon dont Wace et Benoît de Sainte-Maure imitent, aménagent ou rejettent ce modèle. Puis vient l'étude de la forme épique empruntée à différents degrés par les auteurs du corpus. L.M.-M. aborde ici la question des rapports entre épopée et histoire par l'examen précis des matériaux convoqués et par celui de leur utilisation, particulièrement sensible dans les séquences guerrières où se révèlent à la fois l'esthétique de la bataille et une grande technicité, témoignant l'une et l'autre de la complicité qui unit les auteurs et leur public.

7 L'enquête s'achève sur la question du genre de ces œuvres (histoires, gestes?) mais conclut avant tout sur le fait qu'au-delà de l'écriture poétique qui est la leur, elles rejoignent bel et bien les fonctions essentielles de l'historiographie médiévale: célébrer, enseigner, penser le temps.

8 Ce livre de L.M.-M., outre qu'il apporte bien des éléments à notre connaissance des historiens normands de langue vernaculaire, parait un exemple réussi du dialogue indispensable entre historiens et littéraires. 